\title{
Adjustments to the editorial process
}

"People fear change. Ifear that things never change." (Chico Buarque)

When an article is submitted to Dental Press Journal of Orthodontics, the editor-in-chief carries out an initial analysis and decides whether that article is suitable for publication. Should that be the case, the article is sent to three or four reviewers. However, it is immediately sent back to the author if the editor-in-chief considers it unsuitable for publication. For such consideration, the following criteria are applied: low originality level, articles that replicate well-established scientific knowledge only or case reports that do not introduce any important innovations in the treatment of the malocclusion reported. We believe that speeding up this process, especially in cases of refusal, eases the feeling of disappointment caused by a negative response, particularly for young authors.

The process, as it is nowadays, has led some authors to write letters to the editor. In fact, not many letters have been sent, but all questions have been carefully and respectfully analyzed and answered. As in any other submission system, our modus operandi is susceptible to flaws. It is important to emphasize that there is a probability of error in the evaluation process carried out by the editor-in-chief with regard to the quality of the submitted article.

The Dental Press Journal of Orthodontics (DPJO) editorial board has continuously discussed all the questions involved in the peer-review process. And taking advantage of the considerable number of submissions - a fact that is associated with the indexation of DPJO on PubMed ${ }^{1}-$, we decided to introduce a slight change to our editorial process. From 2014 onwards, all submitted articles will be forward to two associate editors for an initial analysis. Should both decide that the article is of low priority, it will be sent back to the author. Conversely, should at least one of the editors decide that the article is suitable for publication, it will continue on the submission process and will be thoroughly analyzed by a group of three to four reviewers.
This initial analysis aforementioned will be carried out by a committee formed by: Daniela Garib, Flavia Artese, Matheus Pithon, Ildeu Andrade, Fernanda Angelieri and Leandro Marques. These eminent Brazilian scientists will be coordinated by the editor-in-chief and will scrutinize the article in order to assess its originality, the quality of its English and whether or not it is in accordance with the standards of the journal.

The aim of this new assessment method is to reduce any bias in the peer-review process of this periodical.

David Normando - editor-in-chief

(davidnormando@hotmail.com)
How to cite this editorial: Normando D. Adjustments to the editorial process. Dental Press J Orthod. 2013 Nov-Dec;18(6):1.

REFERENCES

Normando D. MEDLINE: International recognition of Brazilian orthodontic science development. Dental Press J Orthod. 2013:18(4):1 